International Journal of Social Science And Human Research

ISSN(print): 2644-0679, ISSN(online): 2644-0695

Volume 04 Issue 12 December 2021

DOI: $10.47191 / \mathrm{ijsshr} / \mathrm{v} 4-\mathrm{i} 12-78$, Impact factor-5.586

Page No: 3998-4003

\title{
Reinforcement of Humanitarian Policies to AID Displaced Population in Nigeria and Africa through Coordination, Collaboration and Integration Mechanism
}

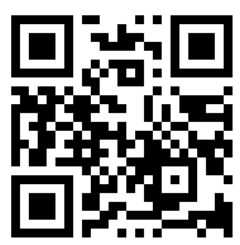

\author{
Oaikhena Igbelokoto E. Marvellous \\ Department of Public Administration, Samuel Adegboyega University, Ogwa, Edo State Nigeria
}

\begin{abstract}
Humanitarian programmes within Africa should be collaborative and integrative in nature, this would easily address the issue of displacement and abandonment, as it shall aid the promotion of the instrumentality of integration within Member states in Africa. Nigeria has over the years played a leading role in Africa affairs based on its foreign policy objectives. The servitude of brotherhood being demonstrated by Nigeria in Africa is a way of uplifting and promoting humanitarian aids in Africa. The problems of displacement of persons, who then becomes refugees in other climes within Africa cannot be overemphasized. People still bear the brunt of the conflict in the north-eastern part of Nigeria, which has resulted in widespread displacement, lack of protection, destruction of infrastructure and collapsed of basic services. The neglect for a concerted effort towards promoting humanitarian services within Africa, has open the doors for the United Nations or International communities to averred that aids and humanitarian services can only be sourced within their domain, thus making African states to be dependent. This study explores the possibilities of enhancing and promoting humanitarian policies in Africa through collaboration and integration. The study further identified areas of neglect in humanitarian services, as policies geared towards humanitarian services has to be sustained, to meet desired objectives. The study employed the secondary data analysis, and adopted the humanitarianism approach. The study recommended that existing humanitarian policies should be strengthened, sustained and adequately implemented to address the issues of humanitarian problems in Africa, while adequate measures are also put in place to monitor its' implementation.
\end{abstract}

KEY WORDS: Humanitarian policies, humanitarian services, IDPs, integration, collaboration.

\section{INTRODUCTION}

Nigeria is said to be the giant of Africa, in terms of size and population. She has also played the big brother in Africa affairs even before 1960, when she got her independence. Unfortunately, some states in northern Nigeria are bedeviled with internal crisis and hostility, ranging from banditry, kidnapping, maiming, raping, killing and destruction of lives and properties. These unfortunate incidents have lead to the displacement of people and subsequent abandonment of homes and communities. Internal displacement had already occurred in Nigeria 53 years ago during the Biafran civil war (1967-1970). More than two million people died and more than (10) ten million people were displaced. The menace of bandits, terrorist, herdsmen and farmers clashes, including flood disasters, has led to the proliferation of IDP camps all over the country.

The crisis in the north-east of Nigeria has continued unabated, as hostilities between Nigerian security forces and armed groups is still on. These unfortunate events has increased the level of kidnapping and assassination of individuals, as school children are often being kidnapped by bandits and taken into bushes for the purpose of collecting ransom. This could be the reason why Reliefweb (2021) reported that, protection needs are formidable, as women and girls are under the threat of violence, abduction and rape, while sexual violence as well as forced and child marriages continue to be reported. The exact number of displacement is difficult to estimate, because many internally displaced persons seek shelter within social networks and relocate to other towns, villages and communities to join other families and clan members.

Therefore, the provision of relieve materials and assistance to these displaced persons, through an act of will and commitment by various agencies, cannot be overemphasized. Relievweb, (2018), reported that, in 2016 and 2017, in close cooperation with the Government of Nigeria, the humanitarian community provided life-saving assistance and helped stabilize living conditions for millions of people. Perhaps it was in line with this that, in 2019, the Government of Nigeria also enhanced its leadership and coordination of humanitarian assistance through the establishment of the Ministry of Humanitarian Affairs, Disaster Management and Social Development (FMHDS), as the Ministry is saddled with the coordination of all humanitarian activities in Nigeria. The Ministry is currently headed by Sadiya Umar Farouk as the Minister, appointed by President Muhammadu Buhari in 


\section{Reinforcement of Humanitarian Policies to AID Displaced Population in Nigeria and Africa through Coordination, Collaboration and Integration Mechanism}

July 2019. The ministry has endeavored to strengthen the institutional framework on humanitarian capacity with respect to protection and assistance to displaced persons and affected individuals in the society.

Meanwhile, it is on record that Africa hosts a larger number of displaced persons and other categories of affected persons as a result of insecurity, natural disaster, inter-ethnic and inter-communal conflicts, diseases, and displacement that are propelled by development projects.

The determination of when each activity is best initiated in relation to humanitarian policy can be optimally achieved, if programmes are properly implemented for the betterment of the target groups, as insecurity makes many locations inaccessible and constrains transport and access to the nominally accessible humanitarian hub locations. However, as partners and common services continue to adapt to the operational challenges of the environment, it is expected that the Minister (FMHDS) may review targets and requirements during 2022, to reach more of the people in need thereby advancing the ministries humanitarian objectives. According to Daniel McCook referenced by Birklad (2015), he posited that, modern policy studies began in 1922, when political scientist, like Charles Merriam sought to connect the theory and crave to understanding the actual activities of government.

The goal of the study is thus to ascertain if the target groups in Nigerian has indeed benefited from such policy initiative as there have been adequate support from the federal government to states, through the Federal Ministry of Humanitarian Affairs, Disaster Management and Social Development, which is expected to promote specific protection of women, vulnerable groups especially children, youth and the aged with disabilities. Reliefweb (2021) reported that, 1.92 million people are displaced internally, and 257,000 have sought refuge in neighboring Cameroon, Chad and Niger. The majority (54\%) of the internally displaced persons (IDPs) have found refuge in host communities.

\section{PROBLEMS HINDERING HUMANITARIANISM}

There is no gainsaying the fact that Nigeria is plagued with the problems of large population of displaced persons, especially in the north-eastern part, through the negative activities of armed groups. This unfortunately has hindered the provision of timely and integrated multi-sector assistance and protection interventions by security forces and humanitarian agencies to the most vulnerable, which has further hindered equitable access to displaced persons, as protection interventions through principled humanitarian actions are sabotaged by the insurgents groups. According to Premiumtimes (2020) it reported that, a humanitarian aid worker and two local officials were abducted by Islamic State West Africa Province (ISWAP) fighters in conflict-plagued northeastern Nigeria. The Jihadists group kidnapped them at a checkpoint in the village of Wakilti in Borno State. It also reported that in June 2020, five humanitarian workers were killed days after being abducted by ISWAP, whose stronghold is on the edge of Lake Chad. Nigeria and indeed Africa humanitarian agencies are faced with providing assistance to people who have been displaced as a result of conflict, violence, natural disaster and project development. The humanitarian community thus, anticipates that the operational constraints that hampered effective response in 2019 might continue or even worsen in 2020 and 2021.

As a result, the untimely increase of humanitarian donor agencies in the delay of support for north-east Nigeria to allow implementation of organizational and enabling common services to reach the targeted groups based on needs and the full potential capacity, is a major problem, hence the problems associated with the operational environment is bedeviled with crisis. For instance in Nigeria, the 2020 multi-sector needs assessment (MSNA) and related Humanitarian Need Overview (HNO), revealed that there shall be an increase in needs across the three north-east states, that is, Bornu, Adamawa, and Yobe states, compared to 2019. This is further characterised by the rise in insecurity, natural disasters (flooding) leading to the problems of newly displaced persons, deepening food insecurity, malnutrition, widespread protection concerns and rights violations, including a constricted humanitarian space and reduced access that hampered effective delivery of humanitarian assistance. Samuel (2021) writing for the European Commission expressed fears that, in north-east Nigeria, 8.7 million people require humanitarian aid. He added that the COVID-19 pandemic came at a time of worsening security and growing humanitarian needs. As a result 4.4 million people in the north east could struggle to eat during the lean season (June-August 2021) without humanitarian assistance, as studies shows that the conflict had resulted in 350,000 deaths, with 314,000 die due to indirect causes. Violence, he said, has led to widespread forced displacement and acute violations of international human rights and humanitarian law, as a result humanitarian agencies are unable to function properly by way of assistance and provision of social security. This could be the reason why Smock (1996) posited that humanitarian assistance provided in recent years by non-governmental organizations (NGOs) in Africa has saved hundreds of thousands of lives.

\section{HUMANITARIAN ASSISTANCE POLICY IN AFRICA}

Several policies had been harnessed over the last decade to deal with humanitarian needs. For instance the African Rehabilitation Institute (ARI), in Harare, Zimbabwe, collaborates with African Governments, African and International Non-governmental Organisations (NGOs), International organisations, and United Nations specialized agencies, to assist member states to enhance disability prevention and rehabilitation services and to ensure the inclusion of disabled persons in all aspects of life. Such collaborations, does encourage member states to initiate and organize programs and events to assist the disabled. This could be the 


\section{Reinforcement of Humanitarian Policies to AID Displaced Population in Nigeria and Africa through Coordination, Collaboration and Integration Mechanism}

reason why Karimi, (2021) posited that "aid is channeled impartially to the affected populations, regardless of their race, ethnic group, religion, gender, age, nationality or political affiliation".

Since the establishment of the Organisation of African Unity (OAU), Africa has been seized with humanitarian crises. The African Union has many years remained committed to a progressive migration agenda recognizing the positive contributions of migrants to inclusive growth and sustainable development.

This development can only be sustained if all relevant partners honour their obligations with respect to humanitarian support to refugees, asylum seekers returnees, stateless persons and internally displaced persons. According to Oaikhena (2021), the suffering in some African states had led women and girls to face systematic discrimination and ostracism. Africa remains a region where $75 \%$ of humanitarian activities are undertaken. Thus, humanitarian actions are expected to preserve, protect and save lives, alleviate sufferings and enhance physical and human security, including dignity of affected persons.

Artwood (2012), the Chair of the Development Assistance Committee, of the Organisation for Economic Co-operation and Development (OECD), once remarked that, humanitarian donors must respond to a wide range of challenges in order to meet the needs of those suffering from crisis and its aftermath. In responding to these humanitarian challenges he said that Development Assistance Committee (DAC) members should be committed to: i) development assistance through, preventing crises, or at least minimizing their risk to the people; ii) humanitarian assistance, to respond to crises; and iii) using a mix of humanitarian and development assistance, to achieve a better transition from a humanitarian situation to longer-term development. This was why Birklad (2015), asserted that "European thinkers like Karl Marx and Max Weber sought to understand how people organize their societies, and how the socially and politically strong can, by accident or design, ignore the desires of the politically weak".

There is also the need to enhance policies towards humanitarian governance, by enhancing the African Union leadership role and mandate through provision of strategic approaches and guidelines for African Union led efforts in conformity with its shared values, norms and standards for humanitarian actions on the continents. This is in compliance with international law, as natural and complex disasters have become increasingly destructive in some African states.

According to USAID (2015), the Policy for Humanitarian Action outlines the context in which USAID's Office of U.S. Foreign Disaster Assistance (OFDA) operates. Thus, the fundamental principles and core values which underpin OFDA's humanitarian activities and the approach OFDA, takes to address the critical humanitarian needs of the most vulnerable disasteraffected populations around the world. In spite of all these challenges and efforts, Africa still lacks a comprehensive and overarching humanitarian policy framework, as the humanitarian and disaster management mechanisms are largely weak and insufficient.

\section{STRENGTHENING NIGERIA POLICY ON HUMANITARIAN SERVICES}

According to the Minister of the Federal Ministry for Humanitarian Affairs, Disaster Management and Social Development (FMHDS), in Nigeria, she said that, the Ministry under the President Mohammadu Buhari lead administration, had performed creditably in the discharge of its activities in the area of disaster management and provision of aids to displaced persons. It has provided leadership and coordination in most matters relating to humanitarian challenges, disasters and social development in Nigeria. According to Oaikhena and Osemeke (2016), they posited that, leaders must be men and women who take their duties, obligations, promises seriously and does everything possible to fulfill them promptly and efficiently.

Thus, development programs geared towards humanitarian services needs to be a win-win, thereby improving the management and distribution of economic resources and contributing more effectively, as the situation demands. Each brings value towards strengthening existing relationship in the handling of humanitarian affairs not only in Nigerian but in Africa at large.

Nevertheless, Nigeria has one of the world's lowest per capita social spending levels resulting in sixty-five percent of the over 200 million citizens living in extreme poverty, as a result Nigeria has the responsibility of promoting effective prompt assistance to alleviate human suffering caused by natural and manmade disasters, this becomes an important expression of the humanitarian concern and tradition of the people. Duerksen (2021), posited that "Nigeria recently surpassed India as home to the most people living in poverty in the world, and its unemployment rate is 33 percent", with youth forming 40 percent of the total population.

Adequate policies in this regard, must be strengthened towards helping displaced population, through the promotion of transparency and accountability in management of humanitarian affairs, targeted towards the reduction of poverty, provision of shelter and health care services, for the benefit of displaced population.

Succinctly, to strengthen these policies and combating these many challenges, USAID seeks to promote stability through improved social services; transparent and responsive governance; a market-led economy; and humanitarian assistance. Such strategies and planning is geared towards saving lives, alleviating human suffering, and mitigating the economic and social impact of disasters. It further, recognizes the links between independent humanitarian action and broader aid policies as the feelings of vulnerability, violence and displacement is reduced, while there is hope of economic development, social empowerment and integration is rekindled. 


\section{Reinforcement of Humanitarian Policies to AID Displaced Population in Nigeria and Africa through Coordination, Collaboration and Integration Mechanism}

\section{COLLABORATIVE EFFORTS TOWARDS HUMANITARIAN SERVICES IN AFRICA}

Humanitarian effort in Africa needs to rebuild livelihoods and restore social and community networks. The humanitarian efforts should seek to achieve long-term solutions to violence, persecution and displacement of persons. Such efforts often provide the desired solutions and affect the overall development programmes put in place by the governments to address humanitarian crisis. Government must thus provide the will to assists its citizens at all times most especially in Africa.

Africa needs to begin to recognize the importance of linking development interventions and collaborative efforts towards humanitarian crises in volatile regions and areas affected by natural disasters, insecurity, and crisis. This linkages within Africa helps in sustaining development and humanitarian emergencies caused by insecurity, poverty and natural disasters. A potent force that often effectively pushes problems to the attention of government is crisis events such as demonstration, violence, industrial disputes and dramatic incidents (Ikelegbe, 2006). Thus, the priority should be to build an open, efficient, effective and globally competitive, integrated and collaborative environment in Africa that will facilitate the development and growth of humanitarian investment. This should be achieved through the introduction of African reform policy targeted at attracting foreign and domestic investment in the area of humanitarian provisions, as the private sector shall also be involved in this process. Nigeria should take the leading role in this. The overall goal is to move Nigeria up the ladder in the area of championing humanitarian services in Africa.

Nevertheless, the overall humanitarian situation and response in Africa, especially in collaboration, encouragement and support, will remain challenging and become major concern, unless effective mechanisms are put in place, as this would result in a large number of displaced persons, refugees and other categories of individuals, culminating in poverty, hunger and diseases. According to Oaikhena, (2021), Africa has been at the receiving end of suffering and maladministration, right from the days of slavery till the present days of poverty associated with neglect. Strengthening the principles of humanitarian policies will help in the promotion of friendly environment in Africa and establish strategic partnership for norms and standards of humanitarian action on the African continent, and on the other hand strengthen the primary responsibility of member states by strengthening their predictive, preventive, response and adaptive capabilities.

As it is possible that developing outstanding and unique humanitarian policies are based on the culture of a country, since Africa is bedeviled with different culture and religious practices. Culture, economic and political ties with other countries expand and enrich foreign relations through cultural diplomacy. This could be the reason why Ekeh and Osaghae (1989) wrote that "in treating people according to their abilities, it should be realized that what is of interest to people depends sometimes on their abilities, although other characteristics may count".

\section{CULTURAL INTEGRATION TOWARDS HUMANITARIAN SERVICES}

To effectively assist internally displaced persons in some of the regions in Africa, proper understanding of the culture, economic and political implications are necessary. For instance in some Africa states the practice of voodoo is still in place, as a result some affected persons might not take kindly to foreign humanitarian aids, due to their believe system, that is, the disaster that lead to their displacement is attributable to the anger of the gods, as a result they are being punished for their unfaithfulness, or that the gods want them to move to other climes. According Ker (2010) Voodoo is a religion, a complex spiritual worldview, the distillation of profound religious ideas that came over from Africa during the slavery era and through time became manifest in a number of traditions in the New World.

Meanwhile, in some traditional African beliefs, some events have a life of its' own. Some things are connected in a flow of causal association. That is why in anguish and pain, many would ask: Why now? Why us?. According to Hegel quoted by Omoregbe (1989), the whole universe is self-projections of the Absolute Spirit who develops itself through conflicts and contradictions, through thesis, antithesis and synthesis.

However, for all its challenges, African remains a place of extraordinary human resourcefulness, a land where the people have so little but have found a way to adorn their lives with imagination. According to Rodney (2005) so long as any African society could at least maintain its inherited advantages springing from many centuries of evolutionary change, then for so long could the superstructure continue to expand and give further opportunities to whole groups of people, to classes and to individuals.

Africa, culturally it is arguably the most vibrant and extraordinary place in the world. Thus, in a time of tragedy and pain, African people, like people everywhere, will find comfort in faith, be it Christianity, Islam or the traditional religion of Voodoo worship. According to Ker (2010), he posited that, the entire global community must do everything they can to support the living and facilitate the rebirth of a nation that has given so much to the world.

Thus, humanitarian services should be extended to all who are displaced in Africa, that is, why collaborative efforts should be encouraged. This could be the reason why the Office of U.S. Foreign Disaster Assistance policy mandate, encompasses the fundamental aims of humanitarian action. In the context of this policy, humanitarian action includes protection and disaster assistance, disaster risk reduction, and efforts to build resilience. The economic and political integration of humanitarian aids drawn upon experiences in the area of conflict analysis has to do with the operational planning, which must adopt the experience and 


\section{Reinforcement of Humanitarian Policies to AID Displaced Population in Nigeria and Africa through Coordination, Collaboration and Integration Mechanism}

knowledge of humanitarian aids in different contexts, thereby maximizing the potential harm, due to an emphasis on the speed and quantity of aid delivered rather than the quality of the aid.

Stockholm forum on peace and development (2019), advocated for a long-term planning of humanitarian aid operations. The constraints for humanitarian aid workers to work cost-efficiently and show positive results within a short time frame has a negative effect on the ability to help populations in the long term. Humanitarian aid has political consequences because the allocation and distribution shapes power dynamics between international and local actors on the ground, so the long-term solution is a better option in other to maintain good quality of supplies for humanitarian aid.

\section{SUMMARY AND CONCLUSION}

Humanitarianism which believed in the value of human life, whereby humans practice benevolent treatment and provide assistance to other humans to reduce suffering and improve the conditions of humanity for moral, altruistic, and logical reasons is the most significant aspect of this study, as it sought and encourage integration and collaboration in the provision of humanitarian aids to displaced people in Africa. The government of each member states in Africa has a fundamental role to play in this regard.

The question then is, should public officials represent the people's interest or the people's will? Several theories have been developed to answer this last and most important question, but none has prevailed. The core aims of African Humanitarian action are to preserve, protect and save lives; alleviate suffering; enhance physical and human security as it relates to the dignity of affected populations, displaced by humanitarian crisis. In order to ensure timely and effective humanitarian assistance, African Union activities should be complemented by appropriate coordination mechanism within the African Union Commission and Member states. The study opined that the role of Nigeria is to support through the reinforcement of humanitarian principles and the enhancement of coordination and consolidation of mechanisms required. As the existing humanitarian and disaster management mechanisms are however, largely weak and insufficient.

These mechanisms require enhancement, coordination and consolidation, for the sake of effectiveness and efficiency. Policy framework needs to be strengthened, this will assist in establishing a strategic approach and guidelines for coordinating and supporting Members states' involvement in its early warning and preventive efforts, in addressing root causes and durable solutions, ensuring adequate preparations to respond to and deal with root causes and the aftermath of humanitarian challenges on the continent.

\section{RECOMMENDATIONS}

The study thus recommended as follows:

- that African Rehabilitation Institute (ARI), Federal Ministry for Humanitarian Affairs, Disaster Management and Social Development (FMHDS) and Humanitarian Assistance and Natural Disaster Support (HANDS), including other humanitarian protection agencies, should put ideas and resources together in the provision of humanitarian services, as these would provide the platform to sign, ratify and enact necessary laws and policies to implement relevant humanitarian protection instruments;

- that the government of Nigeria and indeed Africa should make sure there is a sought of system that translates policy ideas into actual policies that are implemented and have positive effects on the displaced;

- that integration and collaboration within the African continent should be sustained as it would encourage member states to be fully involved in humanitarian activities according to their mandate;

- that member states should reinforce humanitarian commitment towards displaced persons through the various state/traditional leaders, by sending humanitarian aids on time to alleviate the suffering of displace population; and

- that the private sectors in member states should play a key role towards humanitarian efforts, thereby promoting African philanthropism.

\section{REFERENCES}

1) Artwood, J. B. (2012). Towards better humanitarian donorship. 12 Lessons from DAC Peer Reviews. Organisation for Economic Co-operation and Development. https://www.oecd.org/dac/peer-reviews/12lessons.pdf. Accessed 21/8/2021.

2) Birklad, T. A. (2015). An introduction to policy process. Theories, concepts, and models of policy making. ( $3^{\text {rd }}$ edition) New York, Routledge.

3) Duerksen, M. (2021). Nigeria's diverse security threats. Africa center for strategic studies. https://africacenter.org/spotlight/nigeria-diverse-security-threats/ accessed 21/8/2021.

4) Ekeh, P. P and Osaghae, E. E. (1989). Federal character and federalism in Nigeria. Ibadan, Heinemannn educational books ltd. p.293

5) Gbadamosi, H. (2021). Fulanization agenda of Buhari Mohammed is real. Tribune News. 
6) Ikelegbe, A. O. (2016). Public policy analysis. Concept, issues and cases. Lagos: imprint services, p. 87.

7) Ker, T. (2010). Haiti earthquake and voodoo: Myths, ritual, and Robertson. @ National Geographic.com. Assessed $15 / 8 / 2010$.

8) Oaikhena, I. M. (2021). Policy pathways towards poverty reduction in the midst of Covid-19 pandemic in Africa: The case of Nigeria and Democratic Republic of Congo (DRC). Pandemic in the $21^{\text {st }}$ Century: Multidimensional Approaches. edited Conference Proceedings: College of Management and Social Sciences, Samuel Adegboyega University, Ogwa, Edo State, Nigeria. Pp212-222.

9) Oaikhena I. M., and Osemeke M. (2016). Good governance: Role of public servants in Nigeria. Glopbal journal of political science and administration. European Centre for Research Training and Development. Pp. 81-97.

10) Premiumtimes (2020) Jihadists abduct aid worker, local officials in Nigeria. https://www.premiumtimesng.com/ assessed 3-9-2021.

11) Karimi, M. (2021). European civil protection and humanitarian aid operations. @ https://ec.europa.eu/echo/where/africa/nigeria_en. accessed 21/8/2021.

12) Reliefweb (2018). Humanitarian response plan. January - December 2018 @ https://reliefweb.int/sites/reliefweb.int/files/resources/2018_hrp_v5.4.pdf accessed 19/8/2021

13) Reliefweb (2021). Nigeria: 2021 Humanitarian response plan (February 2021). @ https://reliefweb.int/report/nigeria/nigeria-2021-humanitarian-response-plan-february-2021 Published March $16^{\text {th }}$ March, 2021. Accessed 3/8/2021.

14) Rodney, W. (2005). How Europe Underdeveloped Africa: Nigeria. Panaf Publishers Ltd. Pp 160

15) Samuel, O. (2021). European civil protection and humanitarian aid operations. @ https://ec.europa.eu/echo/where/africa/nigeria_en. accessed 19/8/2021.

16) Smock R. D. (1996). Humanitarian assistance and conflict in Africa. United States Institute of Peace. $1550 \mathrm{M}$ Street NW Washiton, DC 200005. Pp 3.

17) Stockholm (2019). The political economy of humanitarian aid and implications for peace mediation: The case of South Sudan. From crisis response to peace building: achieving synergies. United States Institute of Peace. @www.sipri.org/sites/default/files/Session 23_SthlmForum 2019.pdf. assessed 15-8-2021.

18) USAID (2015). Policy for humanitarian action. Office of U.S. Foreign Disaster Assistance. 